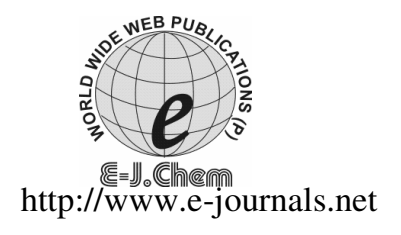

\title{
Spectrophotometric Study of Ternary Complex Forming Systems of Some Lanthanide Metal Ions with Eriochrome Cyanine $R$ in Presence of Cetylpyridinium Bromide for Microdetermination
}

\author{
A. S. DHEPE and A. B. ZADE* \\ Department of Applied Chemistry \\ Smt. Radhikatai Pandav College of Engineering, Nagpur-411204, India \\ *Department of Chemistry, Laxminarayan Institute of Technology \\ R.T.M. Nagpur University, Nagpur, M.S.-440010, India \\ ab_zade18@yahoo.com
}

Received 3 July 2010; Accepted 3 September 2010

\begin{abstract}
Study of coordination compounds of lanthanide elements has received a great attention due to growing applications in science and technology. Number of chromogenic reagents form water soluble colored complexes with lanthanides. Eriochrome cyanine R (ECR) a member of triphenylmethane type of dye has been reported to form green colored complexes with lanthanides and has been used for microdetermination of these metal ions. Addition of cationic surfactant, Cetylpyridinium bromide (CPB), a cationic surfactant sensitizes the color reactions of $\mathrm{Gd}(\mathrm{III}), \mathrm{Tb}(\mathrm{III})$, Dy(III), $\mathrm{Ho}$ (III) and $\mathrm{Lu}(\mathrm{III})$ with ECR. Formation of water soluble, highly colored ternary complexes with a considerable bathochromic shift of about $50 \mathrm{~nm}$ in presence of surfactant has been observed. Optimum reaction conditions and other analytical parameters were also evaluated. Stoichiometric ratio 1:3:3 of Ln: ECR: CPB are responsible for the observed rise in molar absorptivity and sensitivity. Beer's law was obeyed between 0.50 to $13.00 \mathrm{ppm}$. Effective photometric range and molar absorptivity of these ternary complexes have been calculated. Effect of some common interfering ions on determination of these lanthanide metal ions was studied. A simple, rapid and highly sensitive spectrophotometeric method has been proposed for the determination of metal ions understudy.
\end{abstract}

Keywords: Eriochrome cyanine R (ECR), Cetylpyridinium bromide (CPB), Lanthanides [Ln (III)], Ternary complexes.

\section{Introduction}

Lanthanides find very wide applications in modern science and technology and have attracted the attention of the analysts. Gadolinium metal is used in iron, chromium and in some alloys to increase their resistance to oxidation at high temperatures. In the medical 
realm, solutions of gadolinium compounds are used as intravenous contrasts to enhance images in patients undergoing magnetic resonance imaging (MRI). Terbium is used as a dopant in calcium fluoride, calcium tungstate and strontium molybdate which are used in solid-state devices. Terbium can be used with $\mathrm{ZrO}_{2}$ as a crystal stabilizer in high temperature fuel cells. Dysprosium metal is used in permanent magnets for the use in audio speakers and industrial applications and also for magnetostrictive alloys. Holmium is used as a dopant for yttrium-aluminum garnets used in laser surgery. Lutetium is used in cracking and polymerization of catalysts. Lanthanum and yttrium are used in high technology applications, such as in superconductors, supermagnets, laser and alloys ${ }^{1}$.

Several organic reagents have been developed as a binary complex for the determination of these metal ions by various photometric methods and a very few ternary complexation of these metal ions have been reported and discussed in the present investigation. The luminescence signal from a terbium(III)-levofloxacin complex, in a micellar solution of sodium dodecyl sulfate (SDS), using a chemical deoxygenating agent $\left(\mathrm{Na}_{2} \mathrm{SO}_{3}\right)^{2}$ and luminescence sensitization of terbium $\left(\mathrm{Tb}^{3+}\right)$ by formation of ternary complex with ibuprofen (IB) in presence of tri- $n$-octylphosphine oxide (TOPO) and tween-20 as surfactant have been reported ${ }^{3}$. Surfactant (CPB) sensitized analytical reaction of cerium(IV) with some triphenylformazan derivatives was studied by Ahmed and his coworkers ${ }^{4}$. Determination of trace amount of ruthenium(III) by the spectrophotometric method with rhodamine B in micellar medium (CTAB) was studied by Mohsen Keyvanfard ${ }^{5}$. Samarium(III) was determined spectrophotometrically by using chrome azurol $\mathrm{S}$ in presence of cetylpyridinium chloride ${ }^{6}$. Some of the rare earth elements with chrome azurol $\mathrm{S}$ in presence of cetyltrimethylammonium bromide and Triton $\mathrm{x}-100$ were determined spectrophotometrically ${ }^{7}$. 2-Hydroxy-1-naphthaldehyde- $p$-hydroxybenzoic hydrazone as a spectrophotometric reagent was used for the determination of lanthanum(III) in presence of $\mathrm{CTAB}^{8}$. Ternary interaction of naphthochrome green (NCG) with cetyltrimethylammonium bromide $(\mathrm{CTAB})$ and rare earths (REs: Yb, Dy, Er and $\mathrm{Eu}$ ) has been investigated with the microsurface adsorption-spectral correction technique (MSASC) ${ }^{9}$. The solution studies of ternary (1:1:1) complexes of $\mathrm{Eu}(\mathrm{III}), \mathrm{Gd}(\mathrm{III})$ and $\mathrm{Tb}(\mathrm{III})$ with benzoic acid/ its derivatives and uracil/ its halo derivatives in dioxane-water $(30: 70 \mathrm{v} / \mathrm{v})$ medium (ionic strength $I=0.1 \mathrm{~mol} \cdot \mathrm{dm}^{-3}$ $\mathrm{NaNO}_{3}$ ) have been performed ${ }^{10}$. Cationic surfactants, such as cetylpyridinium bromide (CPB) sensitize the color reaction of $\mathrm{Nb}(\mathrm{V})$ with 1-(2-benzothiazolylazo)-2-hydroxy-3-naphthoic acid $\left(I_{a}\right)$, 5-(benzothiazolylazo)2,5-naphthalenediol $\left(I_{b}\right)$, 5-(2-benzothiazolylazo)8-hydroxyquinoline $\left(I_{c}\right)$ and 4-(2- benzothiazolylazo) 2,2 -biphenyldiol $\left(I_{d}\right)$ reagents have also been reported ${ }^{11}$. Lanthanum, holmium and manganese in synthetic ceramics, $\left(\mathrm{La}_{(0.8-\mathrm{x})} \mathrm{Ho}_{\mathrm{x}} \mathrm{Sr}_{0.2} \mathrm{MnO}_{3}\right)$ by using chromogenic agent 5-Br-PADAP [2-(5-bromo-2-pyridylazo)-5-diethylaminophenol] and triton $\mathrm{x}-100$ as a surfactant were determined by spectrophotometric method ${ }^{12}$. The chromophore eriochrome cyanine $\mathrm{R}$ (ECR) was developed to sensitively coordinate $\mathrm{Al}(\mathrm{III})$ and $\mathrm{Fe}(\mathrm{III})$ in presence of cetylpyridinium chloride (CPC) at $\mathrm{pH}$ 4.8.It is reported that trace amounts of $\mathrm{Fe}(\mathrm{III})$ can displace $\mathrm{Al}(\mathrm{III})$ from the $\mathrm{Al}(\mathrm{ECR})(\mathrm{CPC})$ ternary complex to form the $\mathrm{Fe}(\mathrm{ECR})(\mathrm{CPC})$ complex $^{13}$.

Considering vast applications and the increasing demand of more sensitive reagents, the present study has been planned for microdetermination of some lanthanides as ternary complex with higher molar absorptivity and sensitivity which primarily decides the usefulness and its importance. Literature survey reveals that ternary complexes of ECR with $\mathrm{Gd}(\mathrm{III}), \mathrm{Tb}(\mathrm{III}), \mathrm{Dy}(\mathrm{III}), \mathrm{Ho}(\mathrm{III})$ and $\mathrm{Lu}(\mathrm{III})$ in presence of micelle forming cationic 'surfactant CPB have not been reported so far. Result of the experiments carried out with ECR in presence of CPB and its interaction with Gd(III), Tb(III), Dy(III), Ho(III) and Lu(III) have been discussed in present investigation and suggested suitable procedure for microdetermination. 


\section{Experimental}

All the chemicals used were of analytical grade purity. ECR supplied by Sigma chemical company (U.S.A.) and CPB by Aldrich chemical company were used. The purity of CPB was tested by argentometric titration for determination of bromide ion content ${ }^{14}$. The lanthanides used as their oxides and were supplied by Indian Rare Earth Ltd. India, of 99.99 $\%$ purity. The stock solution of ECR of $1 \times 10^{-2} \mathrm{M}$ and $\mathrm{CPB}$ of $1 \times 10^{-1} \mathrm{M}$ strength were prepared. The lanthanide(III) ion solutions of $1 \times 10^{-2} \mathrm{M}$ strength were prepared by dissolving respective oxides in minimum quantity of AR grade hydrochloric acid which were standardized by precipitating metal ions as their oxalates and were estimated volumetrically by using bromopyrogallol red as a complexometric indicator ${ }^{15}$. All subsequent dilutions of desired concentration were made by using double distilled water.

\section{Order of addition of reagents}

Order of mixing of solutions of different reagent was maintained strictly throughout the work. The CPB solution was first added to ECR solution and kept for half an hour. The metal ion solution was then added to this solution and again kept for half an hour to reach complete equilibrium. All the absorption measurements were made by using Systronic Visiscan-167 model spectrophotometer with matched glass cells of $10 \mathrm{~mm}$ light path working on its current supply (220V) device. The pH adjustment was done using Elico Model LI - $10 \mathrm{pH}$ meter with glass and calomel electrode assembly and checked frequently with buffer solution of potassium hydrogen phthalate and borax. The $\mathrm{pH}$ of desired solution was adjusted using hydrochloric acid and sodium hydroxide solution of suitable concentration.

\section{Results and Discussion}

\section{Effect of CPB on absorption spectra of ECR}

Absorption spectra of ECR solution show characteristic $\lambda_{\max }$ at about $500 \mathrm{~nm}$ in low acidic medium (pH 5.5- 6.0) and $432 \mathrm{~nm}$ in alkaline medium $(\mathrm{pH} 7.0$ - 10.0) while in more acidic medium (pH 1.0 - 2.0) at $475 \mathrm{~nm}^{16}$. On addition of CPB in more acidic medium, the absorbance decreases with appearance of new peak at $507 \mathrm{~nm}$ causing marked color change from red to light pink and in more diluted solution to almost colorless. This color change has been achieved in acidic medium due to early dissociation of protons in presence of $\mathrm{CPB}^{17}$. This decolorization might be attributed to the interaction between anionic dye and cationic surfactant as expected.

Decolorizing effect at the $\lambda_{\max }$ of ECR i.e.432 nm in presence of CPB has been observed in the $\mathrm{pH}$ range 6.0- 10.0 and indicated the minimum $1: 1$ ratio ECR to CPB is necessary ${ }^{18}$. When this ratio was reached, absorbance of the reagent remains unaltered even when fivefold excess of CPB has been added. Therefore, the tentative composition of so called "Dye - Surfactant" association may be represented as [ECR (CPB)]. No direct proof of this association could be collected in present investigation as all the attempts have been failed to isolate it from solution as concentration was very low. Similar results were obtained at other $\mathrm{pH}$ values where further studies of ternary complex formation have been carried although effects were less pronounced. Nature of absorbance spectra of ECR was changed in presence of higher amount of mineral salts. Effects caused by the addition of chloride and sulphate ions were less as compared to nitrate ions.

\section{Complex Formation with $\mathrm{Gd}(I I I), T b(I I I), D y(I I I), H o(I I I)$ and $L u(I I I)$}

The spectrophotometeric determination of metal ion with ECR is restricted to the $\mathrm{pH}$ range $0.0-6.0$ because color effect due to deprotonation. The maximum complexation has been observed 
around $\mathrm{pH} 6.0$ in absence and presence of CPB. Width and the position of the bathochromic maxima is closely related to the possibility of using ECR as photometric reagent for metal ion determination as the complexation is associated with bathochromic shift.

Comparative absorption spectra of ECR, ECR+CPB, ECR+ $\mathrm{Ln}(\mathrm{III})$, and $\mathrm{ECR}+\mathrm{CPB}+\mathrm{Ln}(\mathrm{III})$ have been shown in Figure 1(a) for Gd(III) at pH 6.2, Figure 1(b) for Tb(III) at pH 6.2, Figure. 1(c) for Dy(III) at pH 6.0, Figure 1(d) for $\mathrm{Ho}(\mathrm{III})$ at $\mathrm{pH} 6.0$ and Figure 1(e) for $\mathrm{Lu}$ (III) at $\mathrm{pH}$ 6.1.

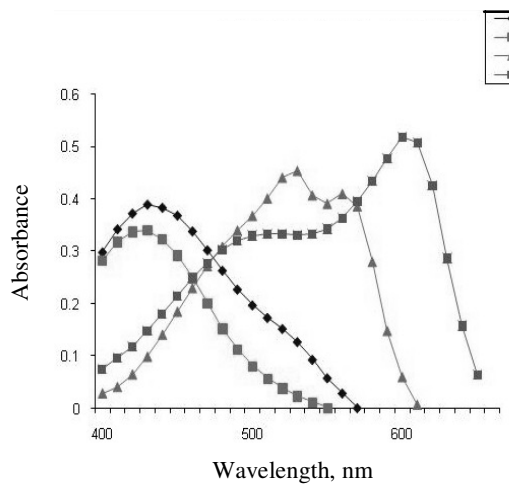

Figure 1(a). Absorption Spectra of ECR at $\mathrm{pH} 6.2$ for $\mathrm{Gd}$

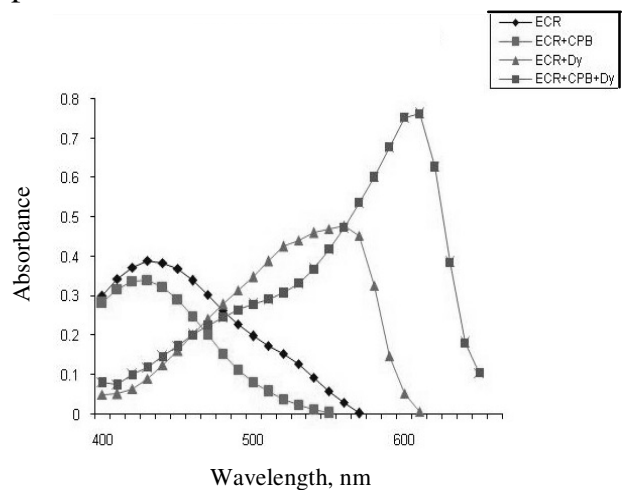

Figure 1(c). Absorption Spectra of ECR Figure 1(d). Absorption Spectra of ECR at at $\mathrm{pH} 6.0$ for Dy

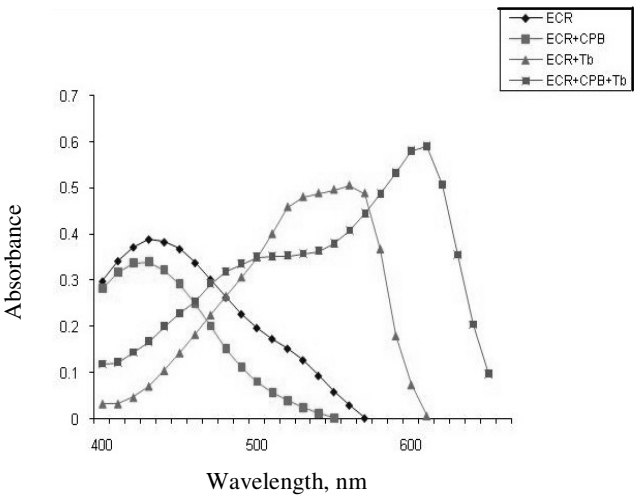

Figure 1(b). Absorption Spectra of ECR at $\mathrm{pH} 6.2$ for $\mathrm{Tb}$
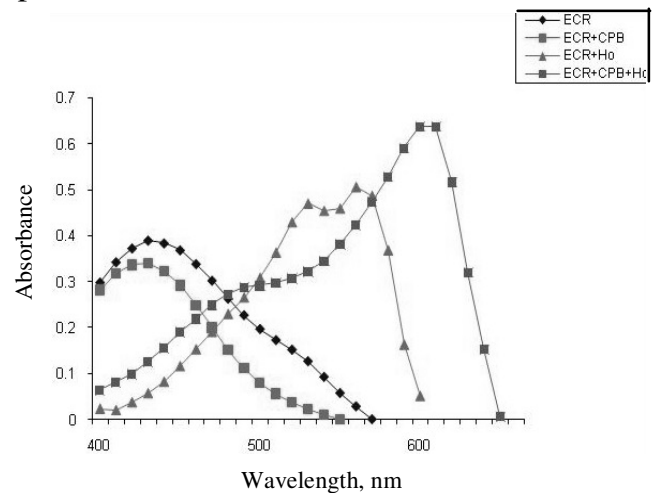

$\mathrm{pH} 6.0$ for Ho

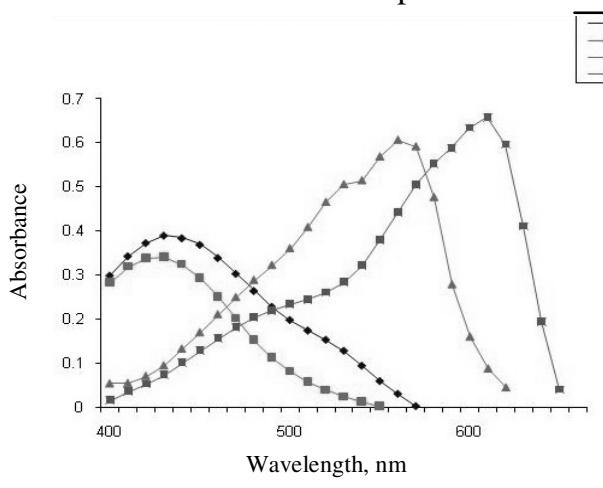

Figure 1(e). Absorption Spectra of ECR at pH 6.1 for $\mathrm{Lu}$ 
In Figure 1(a), at pH 6.2, curve A is for absorption spectra of ECR alone shows $\lambda_{\max } 432 \mathrm{~nm}$, curve B is for ECR in presence of CPB shows $\lambda_{\max } 426 \mathrm{~nm}$ showing small hypsochromic shift, curve C is for ECR- Gd(III) complex shows $\lambda_{\max } 530 \mathrm{~nm}$ indicating binary complexation and curve D is for ECR-CPB- Gd(III) complex shows $\lambda_{\max } 600 \mathrm{~nm}$ indicating formation of strong ternary complex with a bathochromic shift of $70 \mathrm{~nm}$.

In Figure 1(b), at pH 6.2, curve A is for absorption spectra of ECR alone shows $\lambda_{\max }$ $432 \mathrm{~nm}$, curve $\mathrm{B}$ is for ECR in presence of CPB shows $\lambda_{\max } 426 \mathrm{~nm}$ showing small hypsochromic shift, curve $\mathrm{C}$ is for ECR- Tb(III) complex shows $\lambda_{\max } 560 \mathrm{~nm}$ indicating binary complexation and curve $\mathrm{D}$ is for ECR-CPB- Tb(III) complex with a bathochromic shift of $46 \mathrm{~nm}$ shows $\lambda_{\max } 606 \mathrm{~nm}$ indicating formation of strong ternary complex.

In Figure 1(c), at pH 6.0, curve A is for absorption spectra of ECR alone shows $\lambda_{\max }$ $432 \mathrm{~nm}$, curve $\mathrm{B}$ is for ECR in presence of CPB shows $\lambda_{\max } 426 \mathrm{~nm}$ showing small hypsochromic shift, curve C is for ECR- Dy(III) binary complex shows $\lambda_{\max } 555 \mathrm{~nm}$ and curve D is for ECR-CPB- Dy(III) complex shows $\lambda_{\max } 606 \mathrm{~nm}$ indicating formation of strong ternary complex with a bathochromic shift of $51 \mathrm{~nm}$.

In Figure 1(d), at pH 6.0, curve A is for absorption spectra of ECR alone shows $\lambda_{\max }$ $432 \mathrm{~nm}$, curve $\mathrm{B}$ is for ECR in presence of CPB shows $\lambda_{\max } 426 \mathrm{~nm}$ showing small hypsochromic shift, curve C is for ECR- Ho(III) complex shows $\lambda_{\max } 564 \mathrm{~nm}$ and curve D is for ECR-CPB- Ho(III) complex shows $\lambda_{\max } 596 \mathrm{~nm}$ indicating formation of strong ternary complex with a bathochromic shift of $32 \mathrm{~nm}$.

In Figure 1(e), at pH 6.1, curve A is for absorption spectra of ECR alone shows $\lambda_{\max }$ $432 \mathrm{~nm}$, curve $\mathrm{B}$ is for ECR in presence of CPB shows $\lambda_{\max } 426 \mathrm{~nm}$ showing small hypsochromic shift, curve $\mathrm{C}$ is for ECR- Lu(III) complex shows $\lambda_{\max } 564 \mathrm{~nm}$ and curve D is for ECR-CPB- Lu(III) complex shows $\lambda_{\max } 606 \mathrm{~nm}$ indicating formation of strong ternary complex with a bathochromic shift of $42 \mathrm{~nm}$.

Strong complexations in presence of CPB with all metal ions under study with a large bathochromic shift in the formation of ternary complexes with increase in absorbance at shifted wavelength which appeared to be convenient to study the analytical applications further for microdermination.

\section{Effect of $p H$}

Dependence of the wavelength maxima on changes in the acidity of an aqueous solution of $\mathrm{ECR}, \mathrm{ECR}+\mathrm{CPB}, \mathrm{ECR}+\mathrm{Ln}(\mathrm{III})$ and $\mathrm{ECR}+\mathrm{CPB}+\mathrm{Ln}(\mathrm{III})$ have been studied and representative plots have been shown in Figure 2. It has been found that $\lambda_{\max }$ of binary complexes remains constant in $\mathrm{pH}$ range 5.5 to 6.0 in absence and 5.5 to 7.5 in presence of $\mathrm{CPB}$ indicating the $\mathrm{pH}$ range of stability of complex formation. The optimum $\mathrm{pH}$ range of stability where the absorbance of the complex remains constant at the $\lambda_{\max }$ of the ternary complex has been calculated. Optimum $\mathrm{pH}$ range of stability have been calculated at the $\lambda_{\max }$ of binary complexes and was found to be 5.8 to 6.2 for $\mathrm{Gd}(\mathrm{III}), 5.8$ to 6.1 for $\mathrm{Tb}(\mathrm{III}), 5.9$ to 6.2 for Dy(III), 5.7 to 6.0 for $\mathrm{Ho}(\mathrm{III}), 5.5$ to 6.1 for $\mathrm{Lu}(\mathrm{III})$ in absence; and in presence of CPB for ternary complexes 5.7 to 6.4 for $\mathrm{Gd}(\mathrm{III}), 5.7$ to 6.5 for $\mathrm{Tb}(\mathrm{III}), 5.7$ to 6.4 for Dy(III), 5.7 to 6.5 for Ho(III), 5.8 to 6.5 for Lu(III). Thus ternary complexation takes place in wider $\mathrm{pH}$ range as compared to binary complexes and has been observed for all the lanthanide metals understudy. 


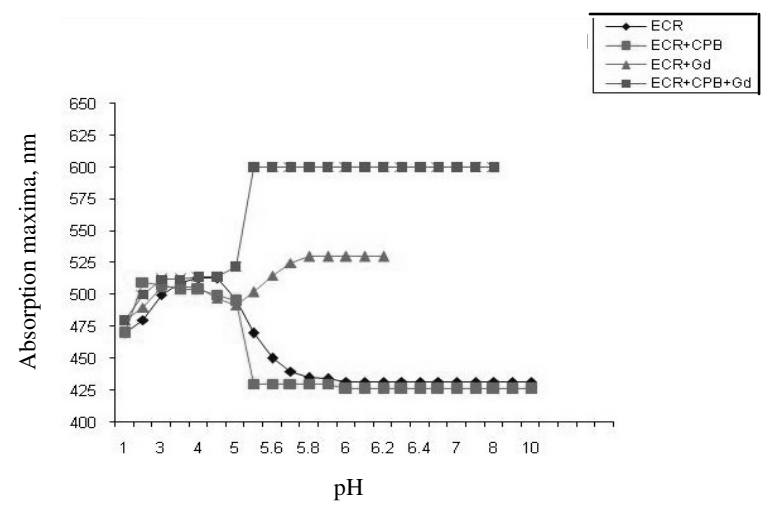

Figure 2. Variation of absorption maxima with $\mathrm{pH}$ for ECR and Gd(III).

\section{Composition and stability constant of complexes}

Composition of complexes was studied by Job's method of continuous variation ${ }^{19}$ and was further confirmed by Mole ratio method ${ }^{20}$. The stoichiometric composition of metal ion and ECR have been found to be1:2 in absence [as shown in Figure 3(a) for Dy(III) at pH 6.2 and $\lambda_{\max } 555 \mathrm{~nm}$ ] and 1:3 in presence [as shown in Figure 3(b) for Dy(III) at pH 6.0 and $\lambda_{\max }$ $606 \mathrm{~nm}$ ] and are in agreement with results reported by Abdallah A. M. et. al.recently ${ }^{21}$. It has been observed that ECR reagent at $\mathrm{pH} 6.0$ exist as $[\mathrm{ECR}(\mathrm{CPB})]$ as one $\mathrm{CPB}$ ion is associated with ECR as discussed earlier and therefore the composition of complexes in presence of CPB may be expressed as $\mathrm{M}[\mathrm{ECR}(\mathrm{CPB})]_{3}$ for all the complexes of lanthanide under study. The tentative formation of ternary complexes may therefore be expressed by an equation (Omitting charges) as follows.

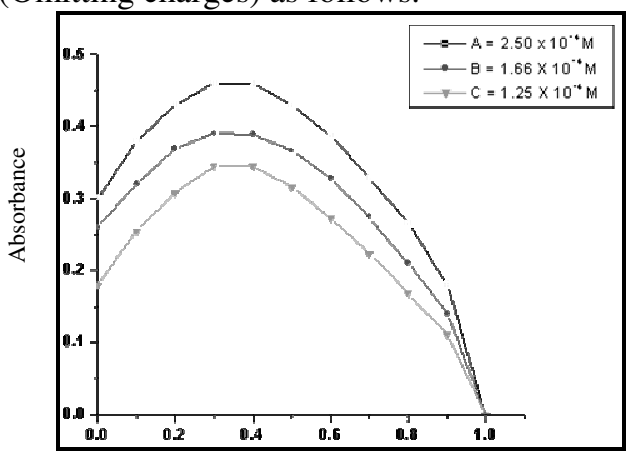

$\left[\mathrm{Dy}^{3+}\right]\left[\mathrm{Dy}^{3+}\right]+[\mathrm{ECR}]$

Figure 3(a). Curves of Job's method of binary complex shows Composition of Dy:ECR as 1:2 at $\mathrm{pH} 6.2$ and $\lambda_{\max } 555 \mathrm{~nm}$.

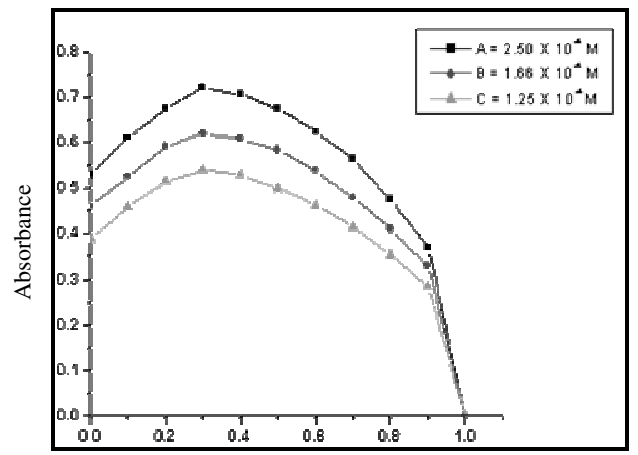

$\left[\mathrm{Dy}^{\mathrm{z}}\right]\left[\mathrm{Dy}^{\mathrm{z}+}\right]+[\mathrm{ECR}(\mathrm{CPB})$

Figure 3(b). Curves of Job's method of ternary complex shows composition of Dy: ECR: CPB as $1: 3: 3$ at $\mathrm{pH} 6.0$ and $\lambda_{\max } 606 \mathrm{~nm}$

$$
\mathrm{M}+3[\mathrm{ECR}(\mathrm{CPB})] \rightarrow \mathrm{M}[\mathrm{ECR}(\mathrm{CPB})]_{3}
$$

The values of $\log \mathrm{K}$ evaluated by Job's method are shown in Table 1 which indicate that the ternary complexes are more stabilized as compared to binary complexes. Values of $\log \mathrm{K}$ $\left\{\right.$ where, $\left.\mathrm{K}=\left[\mathrm{ML}_{3}\right] /\left[\mathrm{ML}_{2}\right][\mathrm{L}]\right\}$ of complexes of the lanthanide metal ions understudy in absence and presence of CPB showed that the value for particular metal in presence of CPB is greater in presence than in absence of CPB. This is due to the formation of stable ternary complexes with modified reagent. 
Table 1. Comparative analytical parameter of the ternary complexes at respective $\mathrm{pH}$ values $\lambda_{\max }$ of ECR at $\mathrm{pH} 6.0=432 \mathrm{~nm}$.

\begin{tabular}{|c|c|c|c|c|c|c|c|c|c|c|}
\hline \multirow[t]{2}{*}{ Parameter } & \multicolumn{2}{|c|}{ Gd(III) } & \multicolumn{2}{|c|}{$\mathrm{Tb}(\mathrm{III})$} & \multicolumn{2}{|c|}{ Dy(III) } & \multicolumn{2}{|c|}{ Ho(III) } & \multicolumn{2}{|c|}{$\mathrm{Lu}(\mathrm{III})$} \\
\hline & A & $\mathrm{P}$ & A & $\mathrm{P}$ & $\mathrm{A}$ & $\mathrm{P}$ & $\mathrm{A}$ & $\mathrm{P}$ & $\mathrm{A}$ & $\mathrm{P}$ \\
\hline$\lambda_{\max }$ of binary complex, $\mathrm{nm}$ & 530 & --- & 560 & --- & 555 & --- & 564 & --- & 564 & --- \\
\hline$\lambda_{\max }$ of ternary complex, $\mathrm{nm}$ & --- & 600 & --- & 606 & --- & 606 & --- & 596 & --- & 606 \\
\hline $\begin{array}{l}\text { Bathochromic } \\
\text { Shift, nm }\end{array}$ & \multicolumn{2}{|c|}{70} & \multicolumn{2}{|c|}{46} & \multicolumn{2}{|c|}{51} & \multicolumn{2}{|c|}{32} & \multicolumn{2}{|c|}{42} \\
\hline $\mathrm{pH}$ of study & 6.1 & 6.2 & 6.0 & 6.2 & 6.2 & 6.0 & 6.0 & 6.0 & 6.0 & 6.1 \\
\hline $\mathrm{pH}$ range of stability & $5.8-6.2$ & $5.5-8.0$ & $5.8-6.1$ & $5.5-7.5$ & $5.9-6.2$ & $5.5-7.5$ & $5.7-6.0$ & $5.5-7.0$ & $5.5-6.1$ & $5.8-7.0$ \\
\hline $\begin{array}{l}\text { Effective } \mathrm{pH} \\
\text { range of stability }\end{array}$ & $5.8-6.2$ & $5.7-6.4$ & $5.8-6.1$ & $5.7-6.5$ & $5.9-6.2$ & $5.7-6.4$ & $5.7-6.0$ & $5.7-6.5$ & $5.7-6.1$ & $5.8-6.5$ \\
\hline $\log \mathrm{K}$ value & 7.25 & 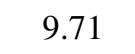 & 7.33 & 9.54 & 7.36 & 9.48 & 7.38 & 9.36 & 7.41 & 9.25 \\
\hline Beer's law range, ppm & $0.5-16.3$ & $0.5-2.58$ & $0.51-16.5$ & $0.5-12.7$ & $0.5-18.2$ & $0.52-13.0$ & $0.53-17.1$ & $0.5-13.2$ & $0.5-17.3$ & $0.5-14.0$ \\
\hline $\begin{array}{l}\text { Effective photometric } \\
\text { Range, ppm }\end{array}$ & $1.0-08.8$ & $1.0-05.0$ & $1.0-08.9$ & $1.0-05.0$ & $1.0-09.1$ & $1.0-05.2$ & $1.0-09.2$ & $1.0-04.7$ & $1.1-09.8$ & $1.1-04.7$ \\
\hline $\begin{array}{l}\text { Average molar absorptivity, } \\
\qquad \mathrm{dm}^{3} \mathrm{~mol}^{-1} \mathrm{~cm}^{-1}\end{array}$ & 14600 & 25200 & 14700 & 23200 & 14200 & 20700 & 14800 & 26000 & 15300 & 32100 \\
\hline Sandell's sensitivity, $\mu \mathrm{g} / \mathrm{cm}^{2}$ & 0.0017 & 0.0014 & 0.0015 & 0.0011 & 0.0016 & 0.0010 & 0.0015 & 0.0013 & 0.0019 & 0.0016 \\
\hline
\end{tabular}

$A$-in absence and $P$ - in presence of $C P B$ 


\section{Analytical applications of ternary complexes}

Formation of intense colored ternary complexes with large bathochromic shift and corresponding increase in absorbance values at shifted wavelength facilitates the analytical measurements for microdetermination of metal ions. Some important analytical parameters and applications for metal ion determination have been summarized in absence and presence of CPB in Table 1.

\section{Rate of color formation and stability of color at room temperature}

Color formation does not depend on reaction time and is almost instantaneous. However the mixtures were kept for $30 \mathrm{~min}$. for complete equilibration before recording their absorbances. Stability of color was tested at room temperature by measuring the absorbance of complex at regular interval of time. The maximum absorbance was achieved in $5 \mathrm{~min}$. after the addition of reactants. Color is quite stable for more than $48 \mathrm{~h}$. at room temperature. The temperature was found to have no effect on color intensity of ternary complexes from $20^{0}-60{ }^{\circ} \mathrm{C}$.

\section{Effect of reagent concentration}

Different volumes of $1.0 \times 10^{-3} \mathrm{M}$ of ECR were taken in different volumetric flasks to which $0.3 \mathrm{~mL}$ of $1.0 \times 10^{-2} \mathrm{M}$ of $\mathrm{CPB}$ was added. $3 \mathrm{~mL}$ of $1.0 \times 10^{-3} \mathrm{M}$ metal ions was then added in each flask and total volume was maintained at $25 \mathrm{~mL}$ and adjusted at respective $\mathrm{pH}$ value, and absorbance readings were recorded at the $\lambda_{\max }$ of the ternary complex. It was found that ECR should be presented at least equal to metal ions concentration to have maximum color development in presence of CPB. However in absence of CPB, reagent needed was eight times as that of metal ion for full color development.

\section{Beer's law and effective photometric ranges}

Linearity between the absorbance of complex and concentration of metal ion was tested by taking different volumes of metal ion solution of $2.0 \times 10^{-4} \mathrm{M}$ in absence and presence of CPB. Concentration of ECR and CPB solutions used were $5.0 \times 10^{-4} \mathrm{M}$ and $5.0 \times 10^{-3} \mathrm{M}$ respectively. Volume of ECR used was $4.0 \mathrm{~mL}$ and of CPB solution used was $1.2 \mathrm{~mL}$ and volume was kept constant at $25 \mathrm{~mL}$ at $\mathrm{pH}$ about 6.0. Absorbance values were measured at their respective wavelength of maximum absorbance $\left(\lambda_{\max }\right)$ for binary complex in absence and at their respective wavelength of maximum absorbance $\left(\lambda_{\max }\right)$ for ternary complex in presence of CPB. As shown Figure 4(a) and 4(b) of absorbance Vs. metal ion concentration, the Beer's law ranges were then calculated and found to be 0.5 to $17 \mathrm{ppm}$ for binary complexes. However in presence of $\mathrm{CPB}$, these ranges have been found to be 0.5 to $13 \mathrm{ppm}$ for ternary complexes.
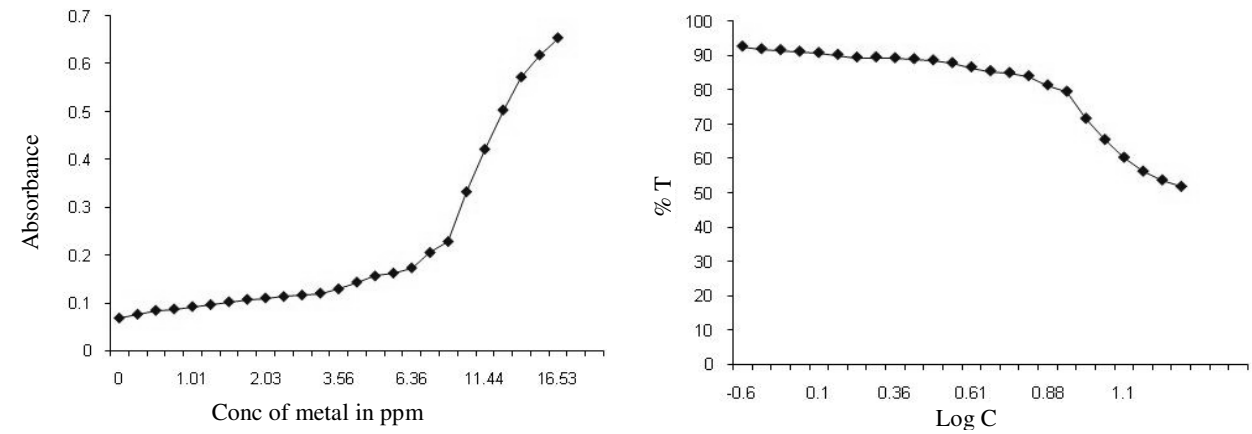

Figure 4(a). Curves of Beer's law for determination of Beer's law ranges of ECR complexes of $\mathrm{Tb}$ in absence of CPB at pH 6.0 and $\lambda_{\max } 560 \mathrm{~nm}$ 
Most effective photometric ranges as derived from straight-line portion of the Ringbom plot $^{22}$ as shown Figure 4(a) and 4(b) (i.e. log of metal ion concentration versus percentage transmittance) have been found to adhere from 1.1 to $9.5 \mathrm{ppm}$ in absence of CPB. However in presence of $\mathrm{CPB}$, these ranges have been found to be 1.0 to $5.0 \mathrm{ppm}$. Present values of photometric ranges are in well agreement with the values reported earlier for metal ions understudy ${ }^{23}$. All metal ions understudy thus can be determined by the present proposed method when present in low concentration.

\section{Sensitivities and molar absorptivities}

Average values of effective molar absorptivities of metal complexes in absence and presence of CPB at the wavelength of study are given in the Table 1 and found to be highest values ever reported in the literature so far for metal ions understudy. It may be stated that the sensitivity in term of molar absorptivity of the complex ion is commonly of little significance for spectrophotometic determination. Its value is usually higher than of net or effective molar absorptivity at given concentration of the metal ion as it is derived from an absorbance value verses blank solution containing same concentration of reagent. Sandell's sensitivity ${ }^{24}$ in absence and presence of CPB against absorbance 0.01 unit for all the metal ions are shown in Table 1. Increase in values of molar absorptivities and sensitivities of ternary complexes, is primarily useful and important tool for determination when present in small concentration which can not be detected by binary complexations using photometric method. Results of the present investigation shows that sensitization of ECR in presence of CPB has taken place and can be used for the microdetermination of metal ions understudy.

\section{Effect of foreign ions}

The present method suffers from lack of specificity but with less interference. The determination is possible in absence of metal ions such as $\mathrm{Sc}^{3+}, \mathrm{Y}^{3+}, \mathrm{Th}^{4+}, \mathrm{Li}^{+}, \mathrm{Fe}^{2+}, \mathrm{Cu}^{2+}$, $\mathrm{Pb}^{2+}$ and $\mathrm{Be}^{2+}$, other lanthanides, $\mathrm{Ag}^{+}, \mathrm{Pd}^{2+}, \mathrm{Hg}^{2+}, \mathrm{In}^{2+}$ and $\mathrm{Au}^{3+}$ and anions such as nitrates, oxalates, citrates, succinates, fluorides and EDTA strongly interfere.

Recommended procedure for microdetermination of individual Gd(III),Tb(III), $\mathrm{Dy}(\mathrm{III}), \mathrm{Ho}(\mathrm{III})$ and $\mathrm{Lu}(\mathrm{III})$

To an aliquot containing 0.5 to $13 \mathrm{ppm}$ of above metal ions [Gd(III)/Tb(III)/ Dy(III)/ Ho(III)/ $\mathrm{Lu}(\mathrm{III})]$ add $5.2 \mathrm{~mL}$ of the modified ECR solution, prepared by adding of $4 \mathrm{~mL}$ of ECR and $1.2 \mathrm{~mL}$ CPB of concentrations $5.0 \times 10^{-4} \mathrm{M}$ and $5.0 \times 10^{-3} \mathrm{M}$ respectively in $25 \mathrm{~mL}$ volumetric flask. Dilute the solution with distilled water to $25 \mathrm{~mL}$ after adjusting $\mathrm{pH}$ for respective metal. Allow the mixture to stand for about $5 \mathrm{~min}$. for full color development. Measure the absorbance of this unknown solution at respective $\lambda_{\max }$ for all the lanthanide metal ions under study against reagent blank of the same $\mathrm{pH}$ prepared in the same manner. Amount of metal ions present in sample solution can be evaluated by comparing this absorbance from calibration curve obtained under similar condition. Results of ten determinations of all the lanthanide metal ions showed standard average deviation of \pm 0.054 .

\section{Conclusion}

Detailed spectrophotometeric study in present investigation have been made for the determination of $\mathrm{Gd}(\mathrm{III}), \mathrm{Tb}(\mathrm{III}), \mathrm{Dy}(\mathrm{III}), \mathrm{Ho}(\mathrm{III})$ and $\mathrm{Lu}(\mathrm{III})$ in absence and presence of CPB. It may be mentioned here that the anionic ECR gets attached with one cationic surfactant $\mathrm{CPB}$ at the $\mathrm{pH}$ of study which results in the decolorization of ECR. All the attempts to isolate the unmetallised ECR-surfactant complex and metallised ECR-surfactant ternary complex have been failed as the product was very much soluble in water. 
Analytical applications of the ternary complexes $i . e$. the metallised ECR in presence of cationic surfactant CPB highlight the following facts for the sensitive microspectrophotometric determination.

1. A bathochromic shift in wavelength of absorbance maxima of about $50 \mathrm{~nm}$ (average from 550 of binary to $600 \mathrm{~nm}$ of ternary) has been observed in presence of cationic surfactant CPB. This shifting in $\lambda_{\max }$ is attributed to the formation of ternary complexes.

2. The values of $\mathrm{pH}$ range of stability and the optimum $\mathrm{pH}$ range of stability show that the greater stability of the ternary complexes in presence of cationic surfactant has been observed in wider $\mathrm{pH}$ range as compared to binary complexes.

3. Large bathochromic shift with higher absorbance values at shifted wavelength of the ternary complexes resulted in to heightened molar absorptivity as compared to binary complexes indicating that the sensitization have been taken place and determination of metal ion can be carried out at lower concentration.

4. Change in the composition from 1:2 in absence to $1: 3$ of ternary complex in presence of surfactant and rise in $\log \mathrm{K}$ values in presence again indicates ternary complexes are more stabilized and is of great interest.

5. The developed procedure appeared to be quite sensitive, precise and reproducible. The commercial exploitation of these reactions needs further investigation.

6. $\mathrm{ECR}$ in presence of $\mathrm{CPB}$ finds significant applications in spectrophotometeric analysis beyond those reported so far. Improved photometric determination may result for many others bivalent and trivalent cations.

Thus the present study suggest really simple and reasonably good method for determination of these metal ions at low concentration by sensitizing the reported reagent ECR, using cationic surfactant and estimation can be carried out at simple laboratory with spectrophotometer and $\mathrm{pH}$ meter.

\section{Acknowledgment}

Authors are grateful to Prof. R. B. Mankar, the Former Director of Laxminarayan Institute of Technology, R.T.M. Nagpur University, Nagpur-44010(MS), INDIA and Prof. N. S. Bhave, the Director of Smt. Radhikatai Pandav College of Engineering, Nagpur-411204 for providing the facilities for carrying out the experimental work.

\section{References}

1. Vijayan S, Melnky A J, Singh R D and Nuttall K, Min Eng., 1989, 41, 13.

2. Juan A Ocana, Manuel Callejon and Francisco Jose Barragan, Anal., 2000, 125, 1851-1854.

3. Salma M Z Al-Kindy and Fakhr Eldin O Suliman, Luminescence, 2007, 22(4), 294-301.

4. Ahmed I S, Amin A S, Issa Y M, Spectrochimica Acta Part A, 2006, 64, 246-250

5. Mohsen Keyvanfard, PWASET, 2008, 33, 2070.

6. Mustafa Soylak and Orhan Türkolu, Talanta, 2000, 53, 125.

7. Preisler, Jan- Jancar, Ludek- Sommer and Lumir, Collection of Czechoslovak Chemical Communications, 1993, 58(6S), 1495-1508.

8. Govinda Chowdary P, Mohan Reddy K P P R, Krishna Reddy V and Raveendra Reddy $\mathrm{P}$, Indian J Chem., 2008, 47A, 1381-1383.

9. Zheng li-xin, Shen Rong and Gao Hong-wen, The Chinese J Process Eng., 2003, 3(5).

10. Shalu Tyagi, Rajeev Kumar and Udai P Singh, J Chem Eng Data, 2005, 50(2), 377-382.

11. Alaa S Amin, Microchem J., 2000b, 65, 261. 
12. Ferreyra R E, Camina J M, Marchevsky E and Luco J M, Fresenius J Anal Chem., 2000, 368(6), 595-600.

13. Hong-Wen Gao, Ling Chen, Qiao-Zhi Yang, J AOAC International, 2005, 88(4), 1231- 1235.

14. Zade A B and Munshi K N in Surfactants in solution, Mittal K L and P Bothorel Editors, Plenum Press, New York, 1989, 9, 261.

15. Zade A B and Munshi K N in Surfactants in solution, Mittal K L and P Bothorel, Editors, Plenum Press, New York, 1989, 9, 713.

16. Chan-il Park and Ki-Won Cha, Bull Korean Chem Soc., 1999, 20(12), 1409.

17. Jarosz M, Chem Anal., (Warsaw), 1988, 33, 675.

18. Chernova R K, Zh Anal Khim., 1977, 32, 1477.

19. Job P, Ann Chim., 1928, 9, 113

20. Musa Ahmad I and Ramaier Narayanaswamy, Pertanika J Sci Technol., 2005, 13(1), 1-21

21. Abdallah A M, Kabil M A, Akl M A, Ismael D S, J Iranian Chem Soc., 2004, 1, 79.

22. Ringbom A Z, Anal Chem., 1939, 115, 332.

23. Jarosz M and Marczenko Z, Anal Chem Acta, 1984, 159, 309.

24. Sandell E B, Colorimetric Determination of Traces of Metals, Chapter III, Interscience Publishers, New York, 1944. 


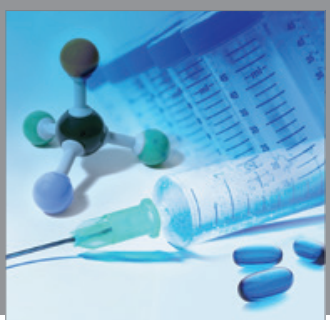

International Journal of

Medicinal Chemistry

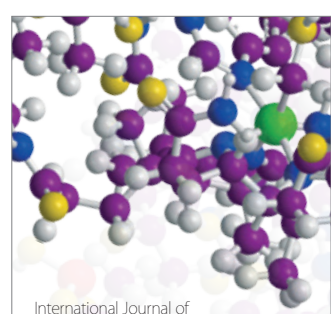

Carbohydrate Chemistry

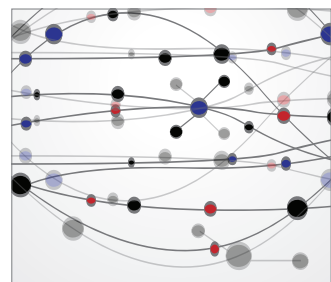

The Scientific World Journal
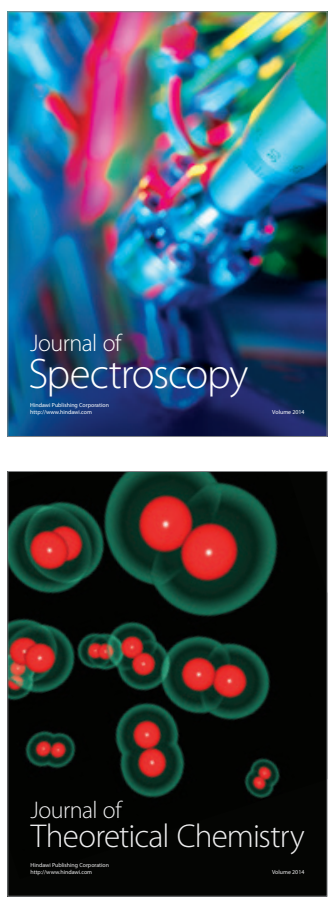
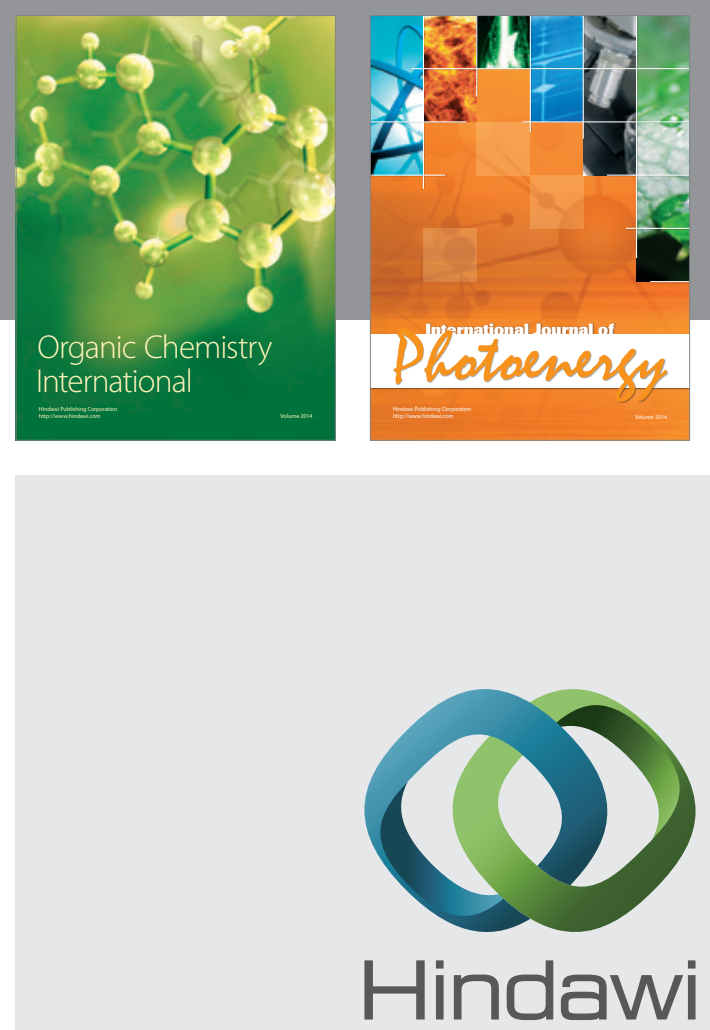

Submit your manuscripts at

http://www.hindawi.com
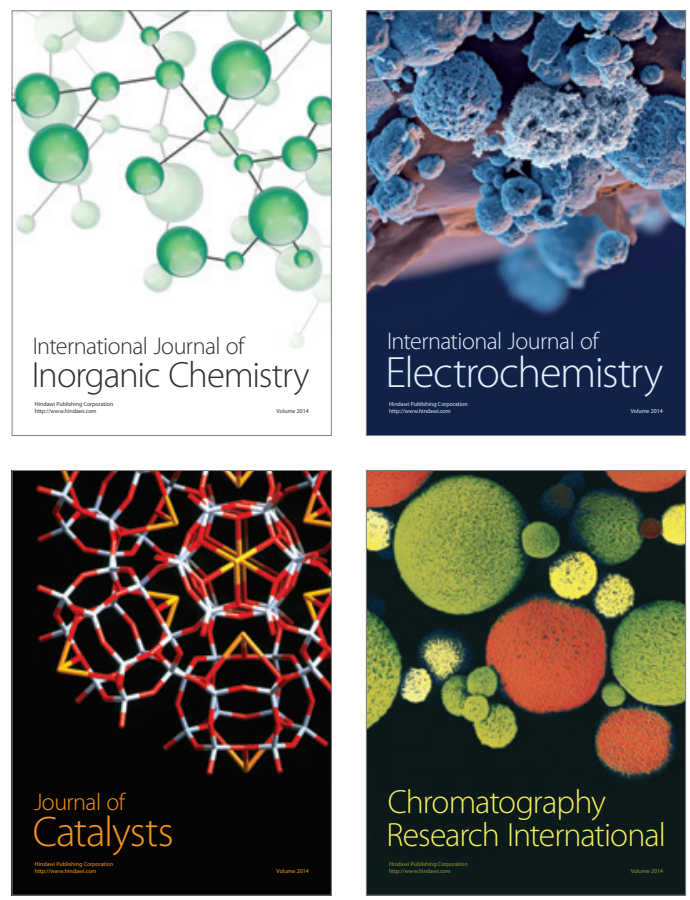
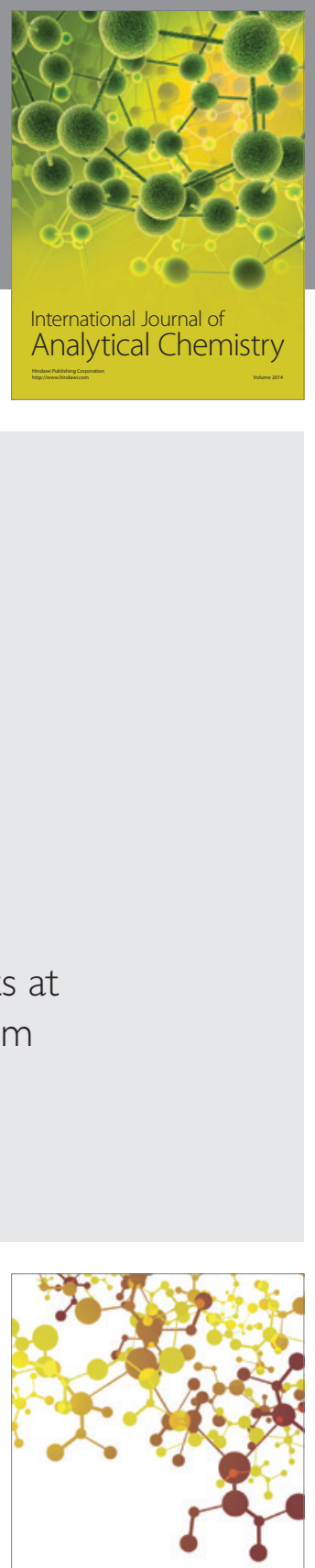

Journal of

Applied Chemistry
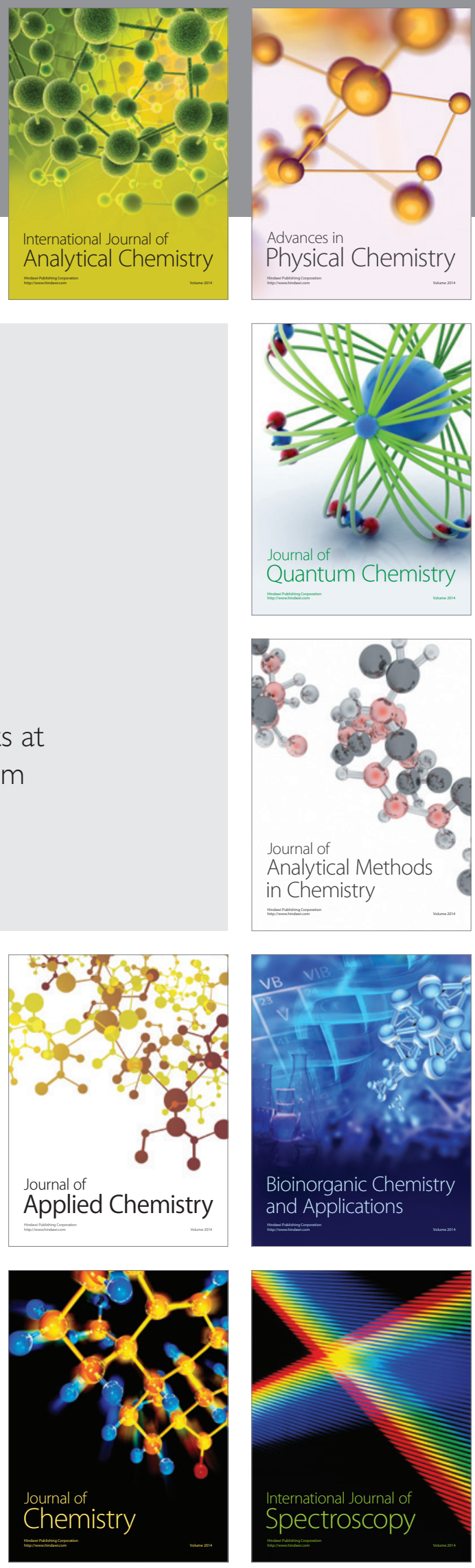